\title{
Pulmonary Involvement in Systemic Hodgkin's Disease
}

\author{
Michihiro Uchiyama and Takashi Ikeda
}

Key words: Hodgkin's disease, pulmonary involvement

(Inter Med 48: 1563-1564, 2009)

(DOI: 10.2169/internalmedicine.48.2183)

A 68-year-old man who was a nonsmoker was referred to our hospital with fever, interstitial pneumonia, general fatigue and cough that had persisted for past 4 months and weight loss of $10 \mathrm{~kg}$. His medical history was unremarkable, and he was not under any medication. Physiological parameters were body temperature, $37.5^{\circ} \mathrm{C}$; heart rate, regular at 80 beats/min and blood pressure, 112/60 mmHg. A physical examination revealed cervical and supraclavicular lymphadenopathy.

Blood analyses showed a white blood cell (WBC) count of $11,830 / \mu \mathrm{L}$ comprising $66 \%$ neutrophils, $17 \%$ lymphocytes, $3 \%$ eosinophils, $2 \%$ basophils, and $12 \%$ monocytes. The hemoglobin concentration was $13.4 \mathrm{~g} / \mathrm{dL}$, and the platelet count was $331 \times 10^{3} / \mu \mathrm{L}$. Biochemical analysis showed increased levels of serum C-reactive protein $(7.94 \mathrm{mg} / \mathrm{dL}$; normal range, $<0.20 \mathrm{mg} / \mathrm{dL}$ ) and soluble interleukin 2 receptor $(3,570 \mathrm{U} / \mathrm{mL}$; normal range $220-530 \mathrm{U} / \mathrm{mL})$. However, the serum levels of lactate dehydrogenase and KL-6 were within normal limits. Arterial blood gas (ABG) values in room air were as follows: $\mathrm{PaO}_{2}$ 98.9 Torr; $\mathrm{PaCO}_{2} 36.2$ Torr; $\mathrm{pH}$ 7.456. Chest radiography revealed coarse reticulonodular opacities in the bilateral lower zone and computed tomography (CT) of the chest revealed systemic lymphadenopathy with multiple central, peripheral parenchymal and subpleural nodules of varying sizes throughout both lung fields, particularly in the bilateral lower regions (Picture 1). Increased uptake in multiple lymph node regions both superior and inferior to the diaphragm, spleen and both lung fields was evident on positron emission tomography (PET)-CT scans. The histological features of the biopsy specimen of a supraclavicular lymph node indicated nodular tumor growth with marked connective tissue proliferation. The nodules contained large atypical cells, which were positive for CD15

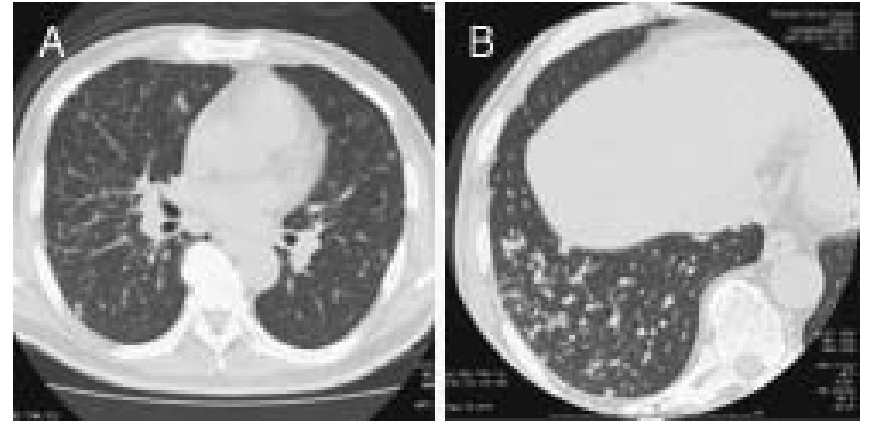

Picture 1.

and CD30 and negative for CD3, CD20, and CD45, on a background of reactive inflammatory infiltrates, suggesting nodular sclerosing-type Hodgkin's disease. Findings of a transbronchial lung biopsy specimen were also consistent with those of Hodgkin's disease.

The patient was staged as IVB, and treated with six cycles of a regimen comprising doxorubicin, bleomycin, vinblastine, and dacarbazine (ABVD). Complete remission was achieved after the third cycle.

Hodgkin's disease can involve the lungs, particularly at the advanced stage. Peribronchial and perivascular infiltration around the bifurcation of the bronchi and pulmonary vessels is the most common type of radiographycally identifiable involvement $(1,2)$. The less common features of homogenous or pneumonic infiltrates might appear radiographically in more peripheral locations $(1,2)$. Therefore, radiographic images such as those of the patient are scarce. The symptoms and findings described herein should be considered as secondary localization of systemic Hodgkin's disease.

\section{References}

1. Jaffe E, Harris N, Stein H, et al. World Health Organization Clasmatopoietic and Lymphoid Tissues. IARC Press, 2001: 237-253. sification of Tumors. Pathology and Genetics of Tumours of Hae- 
Inter Med 48: 1563-1564, 2009 DOI: 10.2169/internalmedicine.48.2183

2. MacDonald J. Lung involvement in Hodgkin's disease. Thorax 32:

664-671, 1977.

(C) 2009 The Japanese Society of Internal Medicine http://www.naika.or.jp/imindex.html 